\section{Failure to confirm evidence for existence of two populations with duodenal ulcer}

A previous study on 339 patients attending a gastrointestinal unit suggested that patients with duodenal ulcer could be divided into two types. ${ }^{12}$ The distinction was based on maximal acid secretion and apparent differences in the prevalence of several clinical features, particularly family history, bleeding and perforation, and ABO blood grouping. In a further series of two groups of 100 patients referred consecutively to the same unit, however, no such distinction could be made. The results of this further study are presented here.

\section{Methods and results}

The two groups of patients, who were investigated between October 1974 and October 1975, were proved radiologically and endoscopically to have duodenal ulcer. In every case the maximal acid output (MAO) was measured in response to $6 \mu \mathrm{g}$ pentagastrin $\mathrm{kg}$ total body weight (TBW). MAO was expressed as the amount of $\mathrm{HCl}$ excreted $/ \mathrm{kg} \mathrm{TBW}$, thereby reducing the difference between the sexes. ${ }^{3}$ Mean MAO levels were used and tests of significance based on a comparison of these. Such tests have a better chance of detecting significance than tests based on contingency tables. The results in each of the two groups are given separately.

The mean MAO levels $( \pm S D$ ) in the two groups were $0.48 \pm 0.19$ and $0.49 \pm 0.20 \mathrm{mmol} \mathrm{HCl} / \mathrm{kg}$ TBW respectively (see table). In the previous study ${ }^{1}$ the MAO was lower in patients of blood $\mathrm{O}$, and this was found again in group 1, though the difference was not significant. In group 2 the MAO was higher in patients of blood group $\mathrm{O}$, though again the difference was not significant.

Only sex affected the MAO. In group 1 the mean MAO levels in male and female patients were $0.50 \pm 0.19$ and $0.41 \pm 0.20 \mathrm{mmol} \mathrm{HCl} / \mathrm{kg} \mathrm{TBW}$ respectively. This difference was significant at the $5 \%$ level ( $t$ test). The corresponding levels in group 2 , however, were $0.49 \pm 0.19$ and $0.46 \pm 0.22$ mmol $\mathrm{HCl} / \mathrm{kg}$ TBW, which were not significantly different. Furthermore, when the results in the two groups were pooled no significant difference at the $5 \%$ level was found between the sexes.

None of the other clinical features examined (see table) could be correlated with MAO. In group 2 the levels were higher in patients with a history of bleeding or perforation, but not significantly so. Moreover, in the previous study $^{1}$ the levels were lower in such patients. The distribution of clinical features was similar in the two groups except for a history of dyspepsia of more than 20 years.

Clinical features and sex distribution of patients in the two groups and mean $M A O$ levels $( \pm S D)$

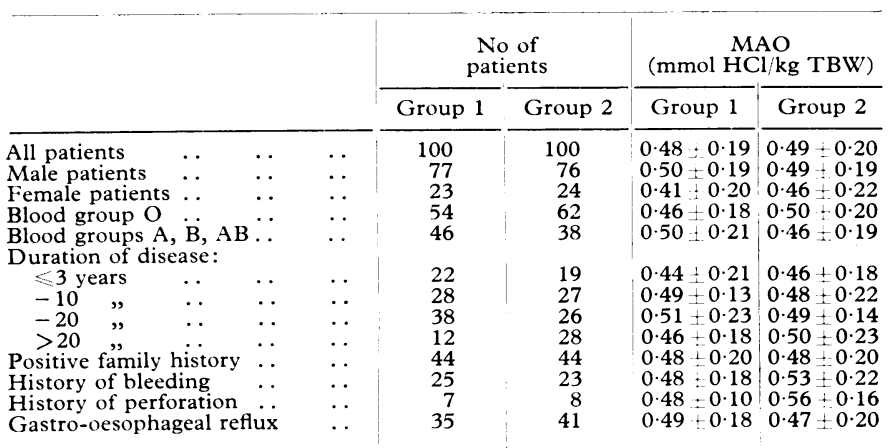

\section{Comment}

These results fail to support the existence of two types of patient with duodenal ulcer, for the MAO appears to be unaffected by any variable. Although expressing the absolute $\mathrm{MAO}$ in terms of body weight reduces the difference between the sexes, it does not abolish it. ${ }^{3}$ Likewise, the possibility of certain clinical features being associated with MAO was not confirmed. Though such discrepant observations in the same unit may seem surprising, experience shows that the usually acceptable level of significance of 1 in $20(P<0.05)$ is often found in this field when a true association is shown later not to exist. $P$ values of $<0.01$ are also often found and shown later to have been due to chance, almost always because of poor control data.

In practice a probability of less than 1 in $1000(P<0.001)$ should be obtained before a difference in $\mathrm{ABO}$ blood group frequency from controls is regarded as significant. ${ }^{4}$ Patients are now referred earlier in the course of the disease and thus the memory of the date of onset is more accurate. Furthermore, during the period covered by this and the previous study (1960-75) there were appreciable social changes in Britain, with an increase in the standards of living and nutrition of the social classes to which most of our patients belonged. Hence, duodenal ulcer altered from being a disease of the well-to-do to that of the "poorer" classes. ${ }^{5}$ Such changes may reflect movement up the social (housing and nutrition) scale of people in occupations that have traditionally been recorded as in classes III-V in the Registrar General's returns.

${ }^{1}$ Lam, S K, and Sircus, W, Quarterly Fournal of Medicine, 1975, 44, 369.

2 British Medical fournal, 1975, 3, 557.

${ }^{3}$ Sircus, W, The Physiology of Gastric Secretion, ed L S Semb and J Myren, p 581. Baltimore, Williams and Wilkens, 1968

${ }^{4}$ McConnell, R B, personal communication.

5 Litton, A, and Murdoch, W E, Gut, 1963, 4, 360.

Department of Statistics and Medical Computing, University of Edinburgh Medical School, Edinburgh

R J PRESCOTT, BSC, PHD, lecturer

Gastrointestinal Unit of the University of Edinburgh, Western General Hospital, Edinburgh EH4 2XU

W SIRCUS, PHD, FRCP, consultant physician and reader in medicine

C L LAI, MB, MRCP, clinical research fellow (seconded on Commonwealth scholarship from the University of Hong Kong)

Department of Medicine, University of Hong Kong, Queen Mary Hospital, Hong Kong

S K LAM, MD, MRCP, lecturer

\section{Consumption coagulopathy after intra-amniotic urea}

Haemorrhage is a well-documented complication of intra-amniotic hypertonic saline and glucose but frank bleeding has not previously been reported after intra-amniotic urea. Several reports have suggested that urea is safer to use than saline and glucose, ${ }^{1-3}$ though McKenzie ${ }^{4}$ showed subclinical changes in many patients treated with urea. No such changes have been observed with oxytocin alone. We report a case of proved consumption coagulopathy resulting from the use of intrauterine hypertonic urea and intravenous oxytocin to induce a mid-trimester abortion.

\section{Case report}

A 24-year-old French primipara was admitted to a private nursing home at 16 weeks' gestation for termination. Amniocentesis was reported as uneventful, a free flow of liquor being obtained. A dose of $80 \mathrm{~g}$ urea in $200 \mathrm{ml}$ normal saline was injected slowly. At the same time $50 \mathrm{U}$ oxytocin in $1000 \mathrm{ml} 5 \%$ dextrose was given intravenously over 12 hours. Although contractions were noted, abortion had not occurred 28 hours later. The cervix was dilated, however, and curettage was performed without further dilatation under general anaesthesia. The fetus and placenta were removed uneventfully. On her return to the ward persistent vaginal bleeding was noted, and a second and later a third examination under anaesthesia was performed and the uterus packed. No residual products of conception or cervical or uterine injury were found. By the third examination the blood was noted to be failing to clot. Fibrinogen titre was $1 / 4$ (control $1 / 32$ ). She was transfused with $3 \mathrm{U}$ triple-strength plasma, $1 \mathrm{U}$ (about $2.5 \mathrm{~g}$ ) fibrinogen concentrate, and 2 units whole blood and transferred to hospital.

On admission she was found to be shocked. No fresh bleeding was noted. The uterus was well contracted but enlarged to 18 weeks' gestation. There was a purpuric area around the site of the amniocentesis. Central venous pressure was monitored and $2 \mathrm{U}$ whole blood and $2 \mathrm{U}$ fibrinogen were given. Results of haematological investiagtions were: haemoglobin $11.7 \mathrm{~g} / \mathrm{dl}$; white cell count $14 \times 10^{9} / 1\left(14000 / \mathrm{mm}^{3}\right)$; platelets $96 \times 10^{9} / 1\left(96000 / \mathrm{mm}^{3}\right)$; prothrombin time $25 \mathrm{~s}$ (control $15 \mathrm{~s}$ ); partial thromboplastin time $57 \mathrm{~s}$ (control $29 \mathrm{~s}$ ); thrombin time $16 \mathrm{~s}$ (control $11 \mathrm{~s}$ ); fibrinogen titre $1 / 4$ (control $1 / 256$ ); and fibrin degradation products (FDPs) greater than $40 \mathrm{mg} / \mathrm{ml}$. Fragmented red cells were seen in the blood film and, together with the 